\title{
Potencial do flavedo (epicarpo) de Citrus aurantifolia cv. Tahiti no controle do bolor verde e da antracnose em citros
}

\author{
Leonardo Toffano ${ }^{1}$, Ivan Herman Fischer $^{2}$, Silvia Blumer ${ }^{1,3}$, Sérgio Florentino Pascholati ${ }^{1,3}$
}

\begin{abstract}
${ }^{1}$ Departamento de Fitopatologia e Nematologia, ESALQ/USP, CP 09, CEP 13418-900, Piracicaba, SP; ${ }^{2}$ Agência Paulista de Tecnologia dos Agronegócios, UPD/Bauru, SP - Brasil, ${ }^{3}$ Bolsista CNPq. Parte da Dissertação de Mestrado do primeiro autor.

Autor para correspondência: Sérgio Florentino Pascholati (sfpascho@usp.br)

Data de chegada: 12/08/2008. Aceito para publicação em: 02/01/2012.
\end{abstract}

1297

\section{RESUMO}

Toffano, L.; Fischer, I.H.; Blumer, S.; Pascholati, S.F. Potencial do flavedo (epicarpo) de Citrus aurantifolia cv. Tahiti no controle do bolor verde e da antracnose em citros. Summa Phytopathologica, v.38, n.1, p.61-66, 2012.

O Brasil é considerado o maior produtor de citros e o maior exportador de suco de laranja. Doenças de pós-colheita representam uma grande perda para a citricultura, sendo que para a exportação de frutos são rígidas as exigências com relação a isenção de resíduos químicos nos mesmos. Patógenos de importância em pós-colheita de citros incluem o Penicillium digitatum, agente causal do bolor-verde e o Colletotrichum gloeosporioides, agente causal da antracnose. Dada a importância econômica que representam estas doenças dos frutos cítricos, tanto em termos de comprometimento da qualidade e dificuldade de controle, a busca de alternativas adicionais que possam viabilizar a capacidade produtiva e garantir a obtenção de frutos com excelentes padrões de qualidade torna-se imprescindível. Portanto, estudou-se os efeitos dos extratos aquosos do flavedo de Citrus aurantifolia var. Tahiti, Lentinula edodes, Agaricus subrufescens (syn. Agaricus brasiliensis), albedo de Citrus sinensis var. Valência e do ácido jasmônico no controle póscolheita do bolor verde e da antracnose e na indução de resistência em frutos de laranjeira Valência (Citrus sinensis). Foi possível observar que o extrato aquoso do flavedo (C. aurantifolia) apresentou efeito inibitório sobre os patógenos, quando tratados em pós-colheita, em função da redução dos sintomas e esporulação. Porém, os extratos de albedo $(C$. sinensis), L. edodes, A. subrufescens e o ácido jasmônico não apresentaram efeitos sobre $P$. digitatum e C. gloeosporioides.

Palavras-chave adicionais: Penicillium digitatum, Colletotrichum gloeosporioides, Agaricus blazei, Lentinula edodes, Agaricus subrufescens, albedo, Citrus sinensis, ácido jasmônico.

\begin{abstract}
Toffano, L.; Fischer, I.H.; Blumer, S.; Pascholati, S.F. Potential of flavedo (epicarp) from Citrus aurantifolia cv.Tahiti on the control of green mold and anthracnose in citrus. Summa Phytopathologica, v.38, n.1, p.61-66, 2012.

Brazil is considered to be the biggest citrus producer and orange juice exporter. Post-harvest diseases represent a great loss in the citriculture, and for many fruits to be exported they should be free of chemical residues. In relation to some pathogens of importance in post-harvest, it can be mentioned Penicillium digitatum (green-mold) and Colletotrichum gloeosporioides (anthracnose). Because of the economical importance of these diseases for citric fruits, in terms of compromising quality and control difficulties, the search for alternative control measures that can make possible to improve the producing capacity of the producers and the obtaining of fruits with excellent quality are indispensable.

Therefore, it was studied the viability of the control of post-harvest diseases in Valência orange fruits (Citrus sinensis) by using the biotic agents flavedo (Citrus auratifolia cv. Tahiti), Lentinula edodes, Agaricus subrufescens (syn. Agaricus brasiliensis), albedo (Citrus sinensis cv. Valência) and the abiotic agent jasmonic acid. It was possible to observe that the aqueous extracts from the flavedo ( $C$. aurantifolia) inhibited the pathogens in Valência orange fruits when treated in post-harvest, based upon symptom and sporulation reduction. On the other hand, the albedo (C. sinensis), L. edodes, A. subrufescens and jasmonic acid had no effects on P. digitatum and C. gloeosporioides in the fruits.
\end{abstract}

Keywords: Penicillium digitatum, Colletotrichum gloeosporioide, Agaricus blazei, Lentinula edodes, Agaricus subrufescens, albedo, Citrus sinensis, jasmonic acid.

As perdas econômicas ocasionadas por doenças de pós-colheita representam um dos principais problemas da citricultura mundial $(7$, 22), embora estudos consistentes sobre a magnitude destas perdas nas condições brasileiras sejam poucos. Em levantamento da incidência de doenças pós-colheita em laranjas comercializadas na Central de Abastecimento de Recife, Dantas et al. (4) detectaram 21,9\% dos frutos analisados com doenças fúngicas, com destaque para Lasiodiplodia theobromae $(11,8 \%)$, confirmando a importância econômica das doenças pós-colheita em frutos de laranja. Em frutos cítricos pode-se destacar o Penicillium digitatum (15), agente causal do bolor verde e o Colletotricum gloeosporioides (20), agente causal da antracnose, os quais são objeto de interesse no presente trabalho.

Para o controle, os fungicidas do grupo dos benzimidazóis são os mais utilizados no Brasil. Entretanto, possuem várias restrições de uso, como a de selecionar estirpes de Penicillium resistentes ao fungicida. A situação se agrava no caso de frutos para exportação, uma 
vez que existem diferenças entre as legislações dos países consumidores na aceitação de determinados fungicidas, bem como na concentração de resíduos tolerada. Alternativas visando à redução do uso de fungicidas vêm sendo pesquisadas e com resultados promissores no controle de vários fitopatógenos em diversas culturas (23), como por exemplo em citros, os quais podem exibir efeito no controle direto dos fitopatógenos (15), mas também na indução de resistência (11).

O potencial do extrato do albedo e do flavedo de laranja na inibição de Phomopsis citri in vitro foi relatado pela primeira vez em 1964, por El-Tobshy \& Sinclair (8), quando se evidenciou que o uso dos mesmos, isoladamente ou em combinação, era efetivo na inibição do crescimento micelial do fungo. Por sua vez, os cogumelos Lentinula edodes (Shiitake) e Agaricus subrufescens (syn. A. brasiliensis) (Cogumelo-da-vida; anteriormente classificado como Agaricus blazei) (13) apresentam substâncias no basidiocarpo e no micélio que ativam o sistema imunológico em animais $(9,16)$. Di Piero \& Pascholati (6) demonstraram que o extrato aquoso do basidiocarpo de L. edodes e do A. subrufescens reduziram a severidade da antracnose (Colletotrichum lagenarium) em plantas de pepino nas condições de casa de vegetação. Além disso, o extrato do A. subrufescens também diminuiu a severidade da mancha bacteriana (Xanthomonas vesicatoria) em plantas de tomate (5). Por fim, o ácido jasmônico é um composto que está presente em diversas plantas, sendo produzido após injúria ou tratamento com eliciadores, podendo apresentar funções hormonais e de defesa contra fitopatógenos e insetos (3).

Em função do exposto, este trabalho teve como objetivo estudar os efeitos dos extratos aquosos do flavedo de Citrus aurantifolia cv. Tahiti, L. edodes, A. subrufescens, albedo de Citrus sinensis cv. Valência e do ácido jasmônico no controle pós-colheita do bolor verde e da antracnose e na indução de resistência em frutos de laranjeira cv. Valência.

\section{MATERIAL E MÉTODOS}

\section{Obtenção dos preparados de L. edodes e A. subrufescens}

Os basidiocarpos dos isolados de L. edodes foram obtidos após o cultivo do cogumelo em toras de eucalipto da espécie Eucaliptus grandis, em local sombreado, no campo, enquanto os de A. subrufescens foram provenientes de cultivos realizados em substratos mantidos no interior de câmaras de produção, onde os fatores ambientais eram controlados. As duas espécies de cogumelos foram fornecidas pelo Departamento de Produção Vegetal (Módulo de Cogumelos), da Faculdade de Ciências Agrárias/ UNESP/ Botucatu. Para a obtenção do extrato aquoso, o pó seco de basidiocarpo recebeu água destilada (14 mL para cada grama), e após 24 horas de incubação a $4{ }^{\circ} \mathrm{C}$, a suspensão foi filtrada em filtro de papel (gramatura: $8 \mathrm{~g} / \mathrm{cm}^{2}$ ) e o extrato utilizado nos testes de proteção de frutos.

\section{Obtenção e preparo do albedo e do flavedo}

Frutos de laranja var.Valência, assintomáticos, com idade aproximada de 10 meses, e frutos da limeira ácida var.Tahiti foram coletados de plantas adultas. No laboratório, a separação do flavedo e albedo foi efetuada com auxílio de uma máquina manual descascadora, a qual retirou inicialmente o flavedo e, posteriormente com o auxílio de uma faca, retirou-se o albedo. O albedo (mesocarpo) de $C$. sinensis var. Valência e o flavedo (epicarpo) de $C$. aurantifolia var. Tahiti foram desidratados em ambiente seco e sombreado, a temperatura ambiente. Após a secagem, os materiais foram moídos em moedor do tipo martelo e transformados em pó. Para a obtenção do extrato aquoso, o pó seco do albedo e flavedo receberam água (10 mL para cada grama), sendo a suspensão filtrada em filtro de papel (gramatura: $8 \mathrm{~g} / \mathrm{cm}^{2}$ ) e os filtrados utilizados nos testes.

\section{Obtenção e preparo do ácido jasmônico}

O ácido jasmônico foi obtido junto a Sigma Chemical Co., sendo inicialmente dissolvido em $1 \mathrm{ml}$ de acetona e subseqüentemente misturado com 8 litros de água (19), para concentração final de 0,5 mM.

\section{Influência dos agentes bióticos e abiótico sobre o bolor verde dos citros}

Os extratos aquosos do albedo, flavedo, L. edodes e A. subrufescens e o ácido jasmônico foram testados no controle pós-colheita de $P$. digitatum nos frutos. Como controles, foram incluídos tratamento com água e com o fungicida thiabendazole (800 ppm).

O delineamento utilizado foi inteiramente casualizado, totalizando 40 frutos por tratamento, sendo realizados quatro experimentos que diferiram no momento de aplicação dos agentes. No primeiro, os agentes foram aplicados nos frutos e logo após a secagem foi efetuada a inoculação do patógeno (Efeito Protetor). No segundo experimento, foi efetuada a inoculação e logo após a secagem da gota do inóculo, efetuou-se a aplicação dos agentes (Efeito Erradicante). No terceiro, os frutos foram inoculados e $24 \mathrm{~h}$ depois tratados (Efeito Curativo). $\mathrm{E}$ no último experimento, os frutos foram tratados e após $48 \mathrm{~h}$, inoculados com o patógeno (Efeito Indutor de Resistência). Nos dois últimos experimentos, os frutos, enquanto aguardavam a aplicação dos agentes ou do inóculo, permaneceram em câmara controlada $\left(25^{\circ} \mathrm{C}\right.$ a $85 \%$ UR) até o final dos testes.

Os frutos foram coletados a partir de laranjeiras existentes na Fazenda Oriçanga, situada no município de Mogi-Guaçu (SP). Posteriormente, foram lavados com água e submetidos a desinfestação superficial utilizando hipoclorito de sódio (200ppm). A inoculação nos frutos foi efetuada a partir de ferimento feito com um sistema de três agulhas. As agulhas estavam em um suporte de borracha e colocadas a uma distância de $1 \mathrm{~mm}$ cada, sendo a profundidade da lesão causada na casca dos frutos de aproximadamente 2 a $3 \mathrm{~mm}$. Os frutos foram inoculados com uma suspensão de esporos $\left(1 \times 10^{5}\right.$ conídios. $\left.\mathrm{mL}^{-1}\right)$, sendo depositada uma gota de $20 \mu \mathrm{L}$ no local do ferimento.

Os frutos foram tratados com as diferentes preparações, via aspersão, utilizando-se $100 \mathrm{~mL}$ de calda por tratamento, recobrindose uniformemente toda a superfície dos frutos. A seguir, os mesmos foram mantidos em câmara controlada a $25^{\circ} \mathrm{C}$ e $85 \%$ UR por 8 dias. Neste período foram realizadas seis avaliações (3, 4, 5, 6, 7, 8 dias), com base na contagem do número de frutos doentes (exibindo sintomas de podridão) e o número de frutos que apresentavam esporulação na superfície da casca (sinais do patógeno).

Influência dos agentes bióticos e abiótico sobre a antracnose Os extratos aquosos do albedo, flavedo, L. edodes e A. subrufescens e o ácido jasmônico também foram testados no controle pós-colheita de $C$. gloeosporioides. Como controles foram usados tratamentos com água e com o fungicida thiabendazole (800 ppm). Os procedimentos que antecederam a inoculação do C. gloeosporioides foram os mesmos utilizados para o bolor verde dos citros. Para a inoculação, discos de micélio de $0,3 \mathrm{~cm}$ de diâmetro foram retirados das bordas das colônias do fungo com 7 dias e colocados no interior de orifícios no flavedo e sobre o albedo dos frutos. Os frutos foram tratados com as diferentes preparações via aspersão, como já descrito. Os frutos foram mantidos em câmara controlada a $23^{\circ} \mathrm{C}$ e $85 \%$ UR por 15 dias. Neste período foram realizadas quatro avaliações $(7,9,12$ e 15 dias após inoculação), com base na contagem do número de frutos 
doentes (com sintomas) e no diâmetro das lesões.

\section{RESULTADOS E DISCUSSÃO}

\section{Influência dos agentes bióticos e abiótico sobre o bolor verde dos citros \\ Efeito protetor - todos os agentes utilizados não inibiram o} aparecimento da doença nas laranjas quando tratadas e logo após submetidas à inoculação (Figuras 1a e 1c). Os sintomas da doença iniciaram-se três dias após a inoculação do fungo $P$. digitatum (Figura 1a), ocorrendo um aumento do número de frutos doentes a cada dia de avaliação em todos os tratamentos. Os frutos começaram a apresentar sinais do patógeno (esporulação) um dia após o início do surgimento da doença, ou seja, a partir do quarto dia após a inoculação (Figura 1c). Foi possível observar que o flavedo da lima ácida Tahiti reduziu o número de frutos doentes e a esporulação. Por sua vez, o ácido jasmônico e o albedo de $C$. sinensis foram os tratamentos que mais estimularam o aparecimento de sintomas e a esporulação do patógeno. Com relação ao último dia de avaliação, não ocorreram diferenças significativas entre os tratamentos, e todos os frutos que ficaram doentes apresentaram esporulação do patógeno.

Efeito erradicante - após os frutos terem sido inoculados e a seguir tratados, todos os agentes utilizados apresentaram baixa inibição no aparecimento de frutos doentes e no número de frutos que apresentaram esporulação do patógeno (Figuras 1 b e 1d). Os resultados evidenciam que todos os agentes utilizados não inibiram o aparecimento da doença, visto que os sintomas começaram três dias após a inoculação do fungo $P$. digitatum (Figura 1b), ocorrendo um aumento no número de frutos doentes a cada dia de avaliação em todos os tratamentos. Os frutos começaram a apresentar sinais do patógeno (esporulação) um dia após o início do surgimento da doença (Figura 1d), ou seja, a partir do quarto dia após a inoculação. Porém, foi possível observar que o flavedo foi o que mais reduziu o número de frutos doentes e de frutos com esporulação em relação aos demais tratamentos. Por sua vez, os extratos do albedo de $C$. sinensis e do A. subrufescens estimularam o aparecimento da doença e a esporulação do patógeno. Com relação ao último dia de avaliação, não se observaram diferenças entre os tratamentos, e todos os frutos que exibiam sintomas, apresentaram esporulação do patógeno.

Efeito curativo - após os frutos terem sido inoculados e $24 \mathrm{~h}$ depois tratados, observou-se que todos os agentes utilizados apresentaram baixa inibição no aparecimento de frutos doentes e no número de frutos que apresentaram esporulação do patógeno, com exceção do flavedo. O aparecimento da doença começou três dias após a inoculação do P. digitatum (Figura 1e), ocorrendo aumento do número de frutos doentes a cada dia de avaliação em todos os tratamentos. Os frutos começaram a apresentar sinais do patógeno (esporulação) um dia após o início do surgimento da doença (Figura 1g), como nos outros casos, a partir do quarto dia após a inoculação. Porém, foi possível observar que o flavedo proporcionou um melhor controle da doença tanto no tocante aos frutos doentes quanto aos frutos com esporulação, quando comparado a testemunha (água). Os extratos do albedo e do A. subrufescens estimularam o aparecimento da doença e a esporulação do patógeno (Figuras 1e e 1g). No último dia de avaliação, o extrato do flavedo apresentou diferença em relação aos tratamentos com albedo e A. subrufescens, quando observados o número de frutos doentes e com esporulação, caracterizando uma inibição por parte do flavedo. Porém, não houve diferença estatística em relação à água, embora os resultados de número de frutos doentes e esporulação tenham sido inferiores no flavedo. Estes resultados se mostram diferentes dos obtidos por Toffano \& Pascholati (21), onde o extrato etanólico de $C$. auratifolia var. Tahiti, quando colocado em contato com o fungo $P$. digitatum, estimulou o crescimento in vitro do mesmo.

Efeito indutor de resistência - após os frutos terem sido tratados e $48 \mathrm{~h}$ depois inoculados, os resultados mostraram que todos os agentes utilizados não inibiram o aparecimento da doença nos frutos quando comparados com a água (Figuras 1f e 1h). O aparecimento da doença começou três dias após a inoculação do P. digitatum (Figura 1f), ocorrendo aumento do número de frutos doentes a cada dia de avaliação em todos os tratamentos. Os frutos começaram a apresentar sinais do patógeno um dia após o início do surgimento da doença (Figura 1h), ou seja, a partir do quarto dia após a inoculação. Ao contrário dos outros experimentos, nenhum tratamento apresentou diferença quanto ao número de frutos doentes e frutos que apresentaram esporulação do patógeno. No último dia de avaliação não se observaram diferenças entre os tratamentos, e todos os frutos que ficaram doentes, apresentaram esporulação do patógeno.

A casca dos citros é um habitat natural do $P$. digitatum, durante a fase patogênica do seu ciclo de vida. Em injúrias causadas nos frutos, durante as fases de colheita e pós-colheita, o esporo germina rapidamente, e inicia a infecção através dos ferimentos (12). O interior do fruto só é colonizado, após o consumo dos compostos presentes no flavedo (14). Estes compostos podem estimular, como também podem inibir o desenvolvimento do patógeno. De acordo com French et al. (10), o óleo retirado do flavedo dos citros, quando incorporado em meio de cultivo ágar-água, estimulou a germinação de $P$. digitatum. Porém, quando alguns compostos foram verificados separadamente, o citral, nonanal, 6-metil-5-hepteno-2-ona, e citronelal estimularam a germinação de conídios de $P$. digitatum, porém, afetaram a germinação de $P$. italicum. Contudo, trabalhos demonstram que o óleo essencial e compostos voláteis, presentes em frutos cítricos, podem interferir na estimulação e inibição do patógeno (18).

Influência dos agentes bióticos e abiótico sobre a antracnose

Efeito protetor - os frutos foram tratados e a seguir submetidos à inoculação do patógeno. Todos os agentes utilizados apresentaram baixa inibição no aparecimento de frutos doentes e no tamanho de lesão por fruto causada pelo patógeno, com exceção do flavedo (Figuras $2 \mathrm{a}$ e 2c). $\mathrm{O}$ aparecimento da doença começou sete dias após a inoculação do fungo C. gloeosporioides (Figura 2a), ocorrendo o aumento do número de frutos doentes a cada avaliação em todos os tratamentos. Foi possível observar que o flavedo do Tahiti também se manteve abaixo da testemunha (água) no tocante ao número de frutos doentes (Figura 2a) e o tamanho das lesões (Figura 2c). No entanto, os demais extratos não apresentaram diferença quanto ao número de frutos doentes e quanto ao tamanho médio de lesão por fruto em comparação a água. Somente no último dia de avaliação, o extrato do flavedo não apresentou diferença significativa em relação aos demais tratamentos, quando observados o número de frutos doentes e o tamanho das lesões. Apesar de não diferir estatisticamente, estes resultados estão de acordo com os apresentados por Toffano \& Pascholati (21), onde o extrato etanólico de $C$. auratifolia var. Tahiti, quando colocado em contato com o fungo $C$. gloeosporioides inibiu in vitro o crescimento, a germinação e a formação de apressórios.

Efeito erradicante - os frutos foram inoculados e em seguida tratados. Todos os agentes utilizados apresentaram baixa inibição no aparecimento de frutos doentes e no tamanho de lesão por fruto causada pelo patógeno (Figuras $2 \mathrm{~b}$ e $2 \mathrm{~d}$ ). $\mathrm{O}$ aparecimento dos sintomas começou sete dias após a inoculação do fungo C. gloeosporioides (Figura 2b), 

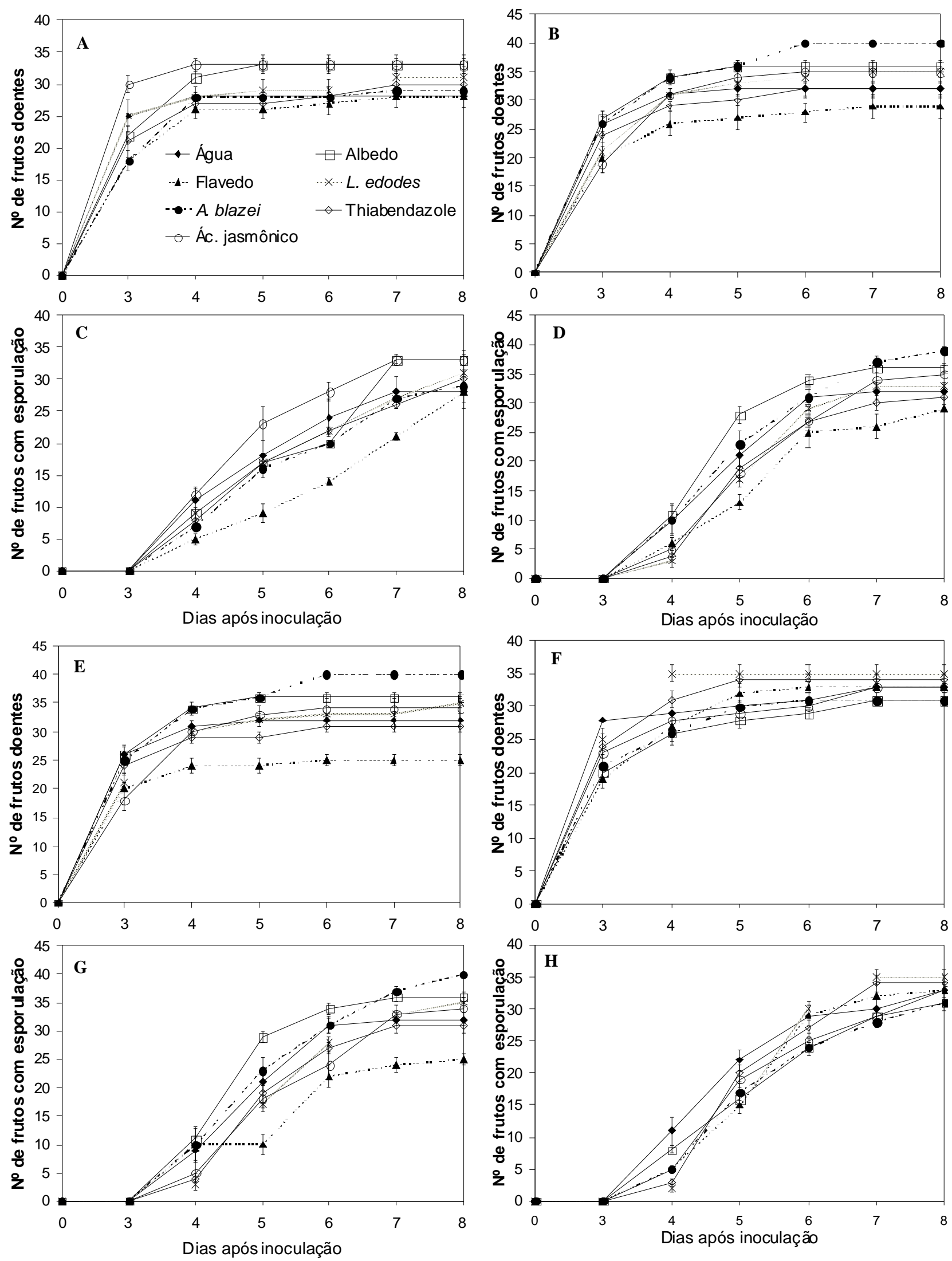

Figura 1. Efeito dos extratos aquosos do albedo de Citrus sinensis cv. Valência, flavedo de Citrus aurantifolia cv. Tahiti, Lentinula edodes, Agaricus blazei (syn. A. subrufescens) e do ácido jasmônico, aplicados em laranjas cv. Valência no controle de Penicillium digitatum inoculado após o tratamento (a,c efeito protetor), imediatamente antes da aplicação dos agentes (b,d - efeito erradicante), 24 horas depois dos tratamentos (e,g - efeito curativo) ou 48 horas (f,h - efeito indução de resistência). Controles: água e thiabendazole. As barras representam a média \pm desvio padrão. 

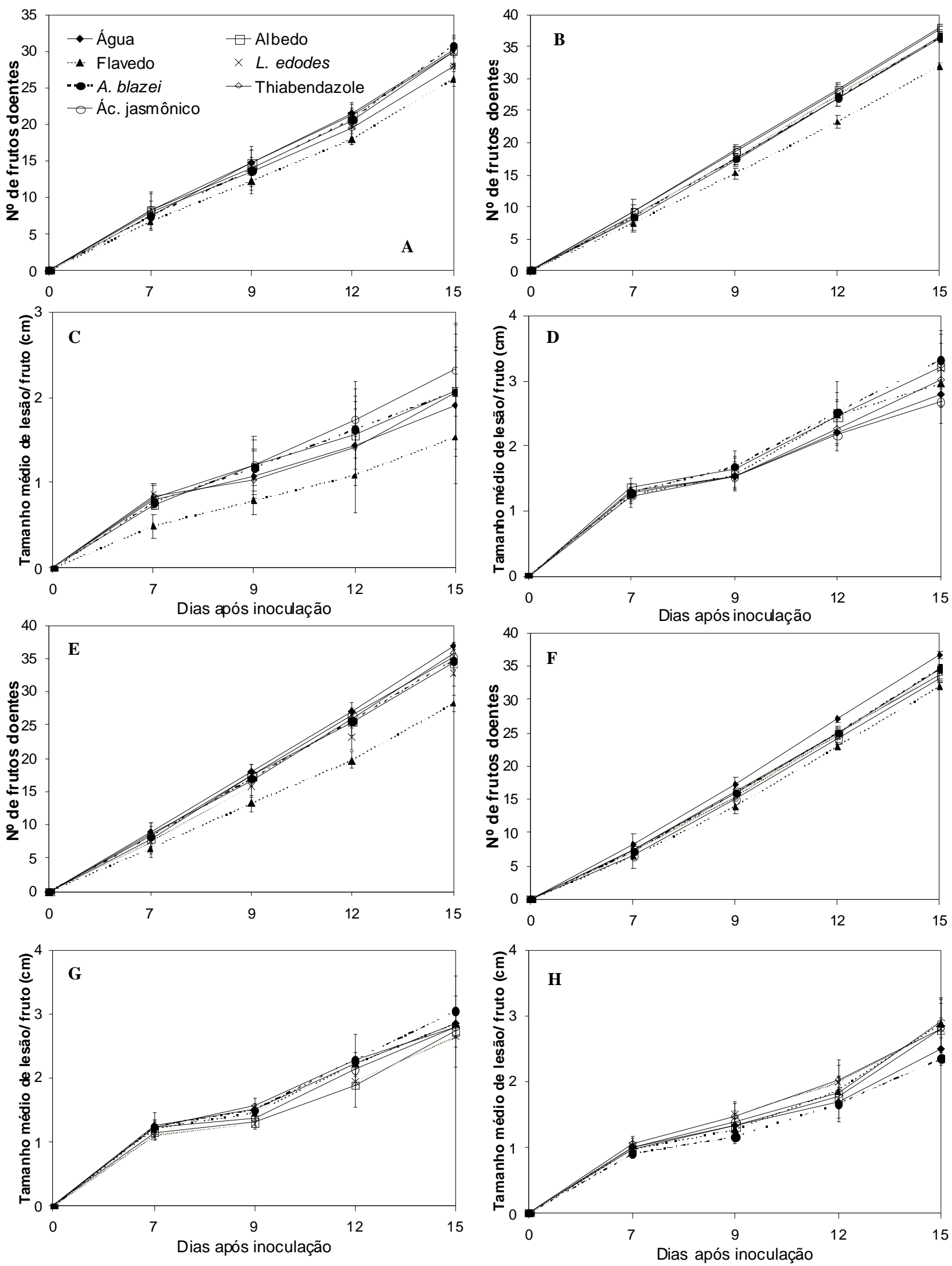

Figura 2. Efeito dos extratos aquosos do albedo de Citrus sinensis cv. Valência, flavedo de Citrus aurantifolia cv. Tahiti, Lentinula edodes, Agaricus blazei (syn. A. subrufescens) e do ácido jasmônico, aplicados em laranjas cv. Valência no controle de Colletotrichum gloeosporioides inoculado após o tratamento (a,c - efeito protetor), imediatamente antes da aplicação dos agentes (b,d - efeito erradicante), 24 horas depois dos tratamentos (e,g - efeito curativo) ou 48 horas (f,h - efeito indução de resistência). Controles: água e thiabendazole. As barras representam a média \pm desvio padrão. 
ocorrendo um aumento do número de frutos doentes e aumento no tamanho das lesões (Figura 2d), a cada dia de avaliação em todos os tratamentos. No último dia de avaliação, de acordo com o teste de Tukey a 5\% de probabilidade, não se observaram diferenças entre os tratamentos, tanto no número de frutos doentes, como no tamanho médio de lesão por fruto.

Efeito curativo - os frutos sofreram inoculação do patógeno e 24 $\mathrm{h}$ depois foram tratados pelos agentes. Todos os agentes utilizados apresentaram baixa inibição no aparecimento de frutos doentes e no tamanho de lesão por fruto causada pelo patógeno, com exceção do flavedo (Figuras 2e e $2 \mathrm{~g}$ ). O extrato do flavedo ocasionou o aparecimento de um número menor de frutos doentes (Figura 2e) e, ao contrário do efeito protetor, não apresentou diminuição no tamanho das lesões (Figura 2g). O aparecimento da doença começou sete dias após a inoculação do C. gloeosporioides (Figura 2e), ocorrendo aumento do número de frutos doentes e aumento no tamanho das lesões, a cada avaliação em todos os tratamentos. Foi possível observar que o flavedo manteve-se abaixo da testemunha (água), somente no tocante aos frutos doentes. No último dia de avaliação, de acordo com o teste de Tukey a $5 \%$ de probabilidade, o extrato do flavedo não apresentou diferença em relação aos demais tratamentos quando observados o número de frutos doentes e o tamanho das lesões.

Efeito indutor de resistência - os frutos foram tratados e $48 \mathrm{~h}$ depois sofreram inoculação do patógeno (Figuras $2 \mathrm{f}$ e $2 \mathrm{~h}$ ). Todos os agentes utilizados apresentaram baixa inibição no aparecimento de frutos doentes e no tamanho de lesão por fruto causada pelo patógeno. $\mathrm{O}$ aparecimento dos sintomas começou sete dias após a inoculação do fungo C. gloeosporioides (Figura 2f), ocorrendo um aumento do número de frutos doentes e aumento no tamanho das lesões (Figura 2h), a cada dia de avaliação em todos os tratamentos. No último dia de avaliação, de acordo com o teste de Tukey a $5 \%$ de probabilidade, não se observaram diferenças entre os tratamentos, tanto no número de frutos doentes, como no tamanho médio de lesão por fruto.

A literatura mostra trabalhos onde frutos cítricos, em pós-colheita, têm mecanismos de resistência ativados, como a síntese das fitoalexinas escoparona e escopoletina, em resposta a diferentes tipos de indutores bióticos e abióticos $(1,2,17)$. Porém, no presente trabalho, ficou evidente que os agentes estudados não demonstraram potencial como indutores de resistência em frutos de laranja Valência.

\section{REFERÊNCIAS BIBLIOGRÁFICAS}

1. Ali, M. K.; Lepoivre, P.; Semal, J. Fosetyl-Al treatment of Phytophthora citrophthora releases a higher scoparone elicitor activity from fosetyl-Al sensitive strain mutant than from an insensitive mutant. Fruits, Paris, Parc d'activites de Courtaboeuf, v. 46, p. 51$55,1991$.

2. Arras, G. Mode of action of an isolate of Candida famata in biological control of Penicillium digitatum in orange fruits. Postharvest Biology and Technology, Amsterdam, v. 8, p. 191-198, 1996.

3. Athayde Sobrinho, C.; Ferreira, P. T. De; Cavalcanti, L. S. Indutores Abióticos. In: Cavalcanti. L. S; Di Piero, R. M.; Cia, P.; Pascholati, S. F.; Vilela De Resende, M. L.; Romeiro, R. S. Indução de resistência em plantas a patógenos e insetos, Piracicaba: FEALQ, v. 13 , p. 51-80, 2005.

4. Dantas, S.A.F.; Oliveira, S.M.A.; Michereff, S.J.; Nascimento, L.C.;Gurgel, L.M.S.; Pessoa, W.R.L.S. Doenças fúngicas pós-colheita em mamões e laranjas comercializados na Central de Abastecimento do Recife. Fitopatologia Brasileira, Brasília, v. 28, p. 528533, 2003

5. Di Piero, R. M.; Pascholati, S. F. Efeito dos cogumelos Lentinula edodes e Agaricus blazei na interação entre plantas de tomate e Xanthomonas vesicatoria. Summa Phytopathologica, Botucatu, v. 30, p. 58-63, 2004.

6. Di Piero, R. M.; Pascholati, S. F. Indução de resistência em plantas de pepino contra Colletotrichum lagenarium pela aplicação de extratos de basidiocarpos de Lentinula edodes e Agaricus blazei. Summa Phytopathologica, Botucatu, v. 30, p. 243-250, 2004.

7. Eckert, J.W.; Eaks, I.L. Postharvest disorders and diseases of citrus fruits. In: Reuter, W.; Calavan, E.C.; Carman, G.E. (Ed.). The Citrus Industry. Berkeley, CA: University of California Press, v. 5, p. 179-260, 1989.

8. El-Tobshy, Z.; Sinclair, J. B. Inhibition in vitro of Phomopsis citri by extracts from orange and by fungicides. Plant Disease Reporter, Washington, v. 48, p. 925-927, 1964.

9. Eira, A.F.; Kaneno, R.; Rodrigues Filho, E.; Barbisan, L.F.; Pascholati, S.F.; Di Piero, R.M.; Salvadori, D.M.F.; Lima, P.L.A; Ribeiro, L.R. Farming technology, biochemistry characterization, and protective effects of culinary-medicinal mushrooms Agaricus brasiliensis and Lentinus edodes: Five years of research in Brazil. In: International Journal of Medicinal Mushrooms. China, v. 7, n. 1-2, p. 281-299, 2005.

10. French R.C.; Long R.K.; Latterell F.M.; Graham C.L.; Smooot J.J.; Shaw E. Effect of nonanal, citral and citrus oils on germination of conidia of Penicillium digitatum and Penicillium italicum. Phytopathology, Lancaster, v. 68, p. 877-822, 1978.

11. Inkha, S.; Boonyakiat, D. Induction of resistance to Penicillium digitatum in tangerine fruit cv. Sai Num Phung flavedo by hot water treatment. Songklanakarin Journal of Science Technology, Songkhla, v. 32, p. 445-451, 2010.

12. Kavanagh J.A.; Wood R.K.S. The role of wounds in the infection of oranges by Penicillium digitatum Sacc. Annals of Applied Biology, Cambridge, v. 60, p. 375-383, 1967.

13. Kerrigan, R.W. Agaricus subrufescens, a cultivated edible and medicinal mushroom, and its synonyms. Mycologia, Lawrence, v. 97, p. 19-24, 2005.

14. Klotz L.J. Some microscopical studies on Penicillium digitatum decay of citrus. Phytopathology, Lancaster, v. 20, p. 251-256, 1930 .

15. Mattos, L. P. V. de. Controle de Guignardia citricarpa e Penicillium digitatum em laranja com óleos essenciais e agentes de biocontrole. Tese de doutorado (PPG em Agronomia - Proteção de Plantas) FCA/UNESP, Botucatu. 104 p. 2010.

16. Mizuno, T. Kawariharatake, Agaricus blazei Murril: medicinal and dietary effects. Food Review International, New York, v. 11, n. 1, p. 167-172, 1995.

17. Rodov, S.; Ben-Yehoshua,D.; D’Hallewin,G.; Castia,T. Accumulation of phytoalexins scoparone and scopoletin in citrus fruits subjected to various postharvest treatments. Acta Horticulturae, The Hague, v. 1, n. 381, p. 517-523, 1994.

18. Song, Hee-Sun. Antimicrobiology. In: Sawamura, M. (ed). Citrus essential oils: flavor and fragrance. John Wiley \& Sons, New Jersey. p. 264-296. 2010.

19. Thaler, J.S. Jasmonic acid mediated interactions between plants, herbivores, parasitoids, and pathogens: a review of field experiments in tomato. In: AGRAWAL, A.A.; TUZUN, S.; BENT, E. (Ed.). Induced plant defenses against pathogens and herbivores. St.Paul: APS Press, 1999. p. 319-334.

20. Timer, L. W.; Brown, J. B.; Zitko, S. E. The role of Colletotrichum spp. In: postharvest anthracnose of citrus and survival of C. acutatum on fruit. Plant Disease. St. Paul, 1998. v. 82. p. 415-418.

21. Toffano, L.; Pascholati, S. F. Efeito dos extratos do albedo de Citrus sinensis e flavedo de Citrus aurantifolia no crescimento micelial, germinação e formação de apressório de Guignardia citricarpa, Penicillium digitatum e Colletotrichum gloeosporioides. Summa Phytopathologica, v. 31, suplemento, p.13, 2005 (Resumo).

22. Tuset J. J. Podredumbres de los frutos cítricos. Valencia: Conselleria d' Agricultura i Pesca. Generalitat Valenciana, 1987. 206 p.

23. Viecelli, C.A.; Stangarlin, J.R.; Kuhn, O.J.; Schwan-Estrada, K.R.F. Indução de resistência em feijoeiro a mancha angular por extratos de micélio de Pycnoporus sanguineus. Summa Phytopathologica, v. 36, n.1, p.73-80, 2010. 